\title{
The Improved Construction of Reinforced-concrete Support of Slope Mouth
}

\author{
Pershin Vladimir V. ${ }^{\mathrm{a}}$, Vojtov Michail D., Budnikov Pavel M. \\ T. F. Gorbachev Kuzbass State Technical University \\ Kemerovo, Russian Federation \\ ae-mail: L01BDV@yandex.ru, ${ }^{\mathrm{b} e-m a i l: ~ b u d n i k o v p m @ m a i l . r u ~}$
}

\begin{abstract}
During the construction of inclined shafts mouths in Kuzbass mines cast-in-situ concrete or reinforced concrete support is applied. Due to coal production increase, there is a necessity to build new coal enterprises, and as a consequence, the necessity to construct inclined shafts and mouths of the inclined shafts in coal mines. As the reinforcement of concrete support, metal frames of H-beams [1] or special mining profile are used. Sometimes interlocks do not fully cope with the task. The type ZPKm interlock was tested in JSC KuzNIIshahtstroy, in the result of these tests the dependences of vertical displacement of the interlocks from the vertical load were received. The authors of the article propose the interlock which is patented under number 77906. Also the tests of metal frame supports in tough and flexible conditions were carried out. On the basis of tests, the dependences were constructed, they became the basis for the development of a new reinforced concrete support construction which was patented \# 59726.
\end{abstract}

Keywords-interlock, special structural iron of SVP type, metal frame support, cast-in-place concrete support, experiment results.

\section{INTRODUCTION}

The practical use of underground structures is one of the urgent problems, as in this case underground space is an additional source of natural resources. Thus, the construction of capital mine workings in mining industry will continue to increase. In this regard, an increase in labor intensity, quality improvement and a decrease in underground construction time are very important. This refers to the mouths of inclined shafts in coal mines. The choice of cross sectional shapes and designs of support of the mouth of the inclined shafts must be reasonable [2] [3].

Usually the mouth is driven to the bedrock. The mouth is supported over its full length by cast-in-place concrete or reinforced concrete, precast concrete is used less often [1] [4]. The metal frames made of H-beams [5] or special mining profile are used as reinforcing material which can be used as reinforcing cage during construction of concrete support [2].

In traditional metal compressible support of mine workings, the interlock is the weakest constructional unit.

\section{MATERIALS AND METHODS}

It is known that carrying capacity of special structural iron of SVP 27-33 type (special interchangeable profile) in accordance with steel quality is varying in the range of 406-
$700 \mathrm{kN}$, the interlock can carry maximum load of $210 \mathrm{kN}$.

Together with usual compressible locks, the reinforced interlocks of ZPKm type (modernized locks for compressible support) were developed (Fig. 1) to be used in roadways influenced by stoping, and also in permanent mine roadways where the forecasted roof strata motion is higher than $300 \mathrm{~mm}$.

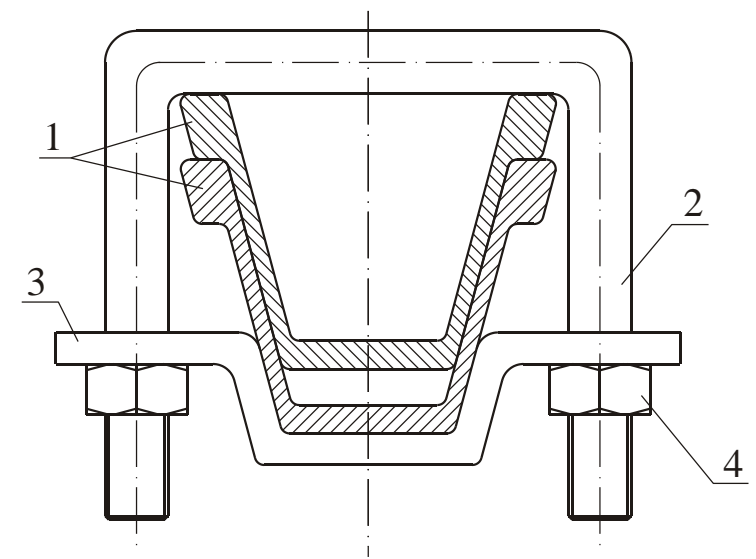

1 - special section SVP; 2 - clamp; 3 - baffle with special structural iron form; 4 - nut

Fig. 1. Reinforced interlock of ZPKm type

Four typical sizes of the support KMP-A3U-16-27 (metal compressible arch tree link unified support with cross section area of $16 \mathrm{~m}^{2}$ made of special structural iron of SVP 27) (Fig. 2), KMP-A3U-13-22, KMP-A3U-11-22, and KMP-A3U-1022 were tested using three frames of each typical size [6] [7].

Following the analysis and processing of the data obtained from JSC KuzNIIshahtstroy, the dependences were constructed and analytical formula of the dependence of $\mathrm{ZPKm}$ interlock vertical motion on the vertical load was received for different typical sizes of the support (Fig. 2) [8].

The increased values of support yield load provided by the usage of ZPKm interlocks in accordance with regulatory documents allow an increase of the metal supports installation spacing. This provides saving of metal support per $1 \mathrm{~m}$ of roadway length.

The authors of the article considered the support function in flexibility condition; it is accompanied by pressing in of a cramp rod of the interlock in the flange of a beam and by 
sharp deformation of a cramp in threaded zone. The support function in flexibility condition due to the firm connection of a shaped strip to the stand is being done while a cramp rod is sliding towards the flange of a beam, because of huge contact stress it causes metal "compressing" of the a cramp rod with sharp decrease of contraction of support elements and decrease of support load capacity in flexible condition, but ingress of a beam tail from a stand pan doesn't promote to load capacity increase [9].

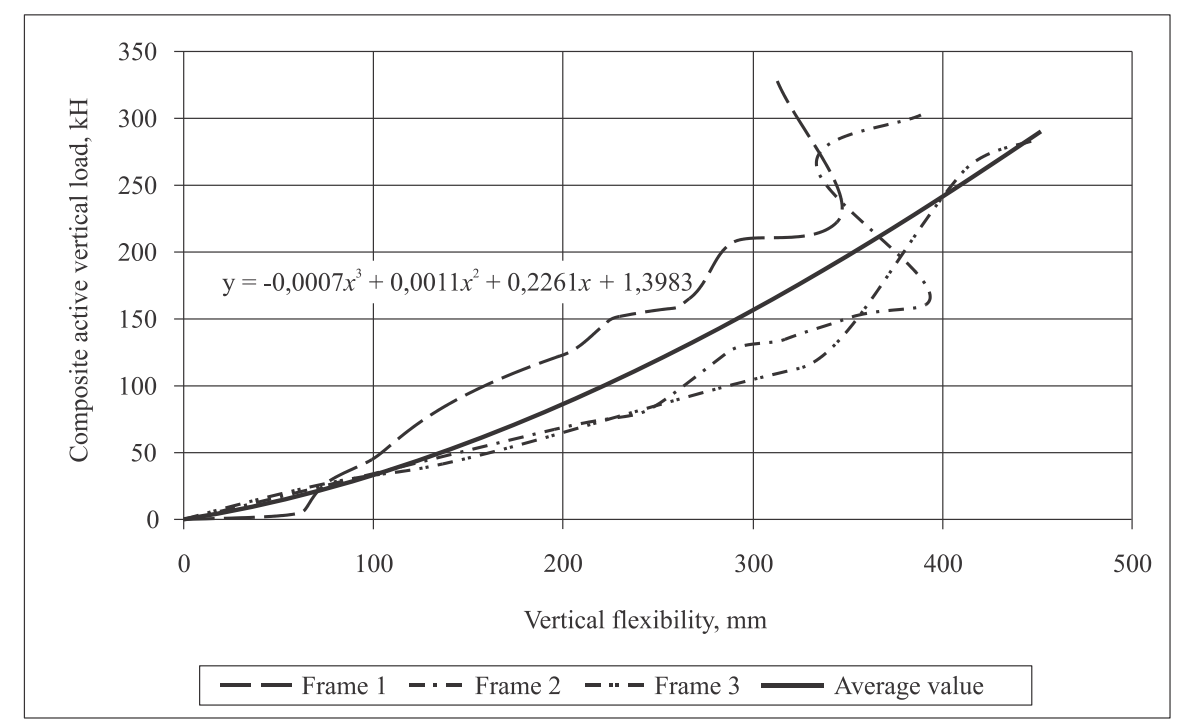

Fig. 2. The dependences of vertical connection upsets ZPKm of a support KMP-A3U-16-27 from vertical load

The interlock of support elements with a cramp and a plain strip from the bar has none of the above drawbacks. In such interlocks plain strips have low flexing strength, and support load capacity in flexibility condition is $0,25-0,4$ from the support load capacity in tough condition, and this is its main drawback.

The patented interlock has the following features: a cramp

a)

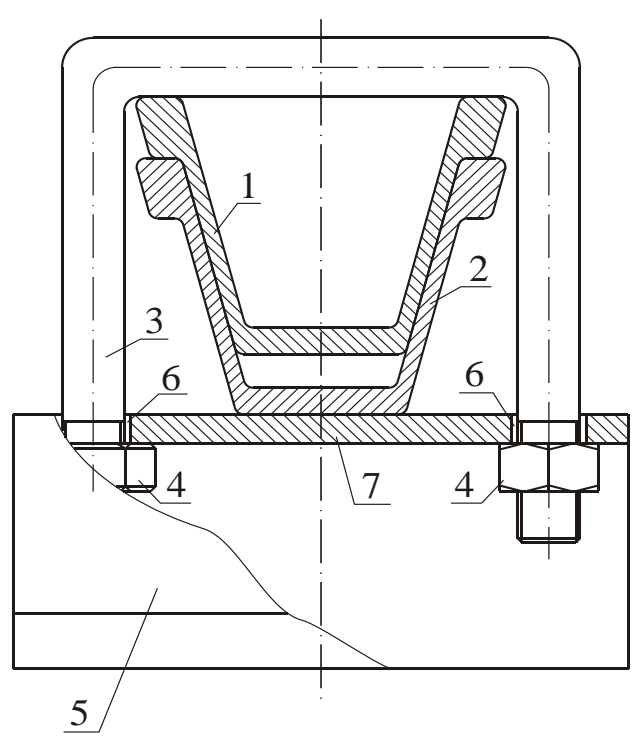

(a) - interlock; with nuts, a rectilinear strip with holes, the determined goal is reached due to the fact that the strip is done as a section of special structural iron with holes in bottom of its pan inside of which there are nuts.

In Fig. 3 (a) the support section in interlock connection is shown, Fig. 3 (b) shows the side view.

b)

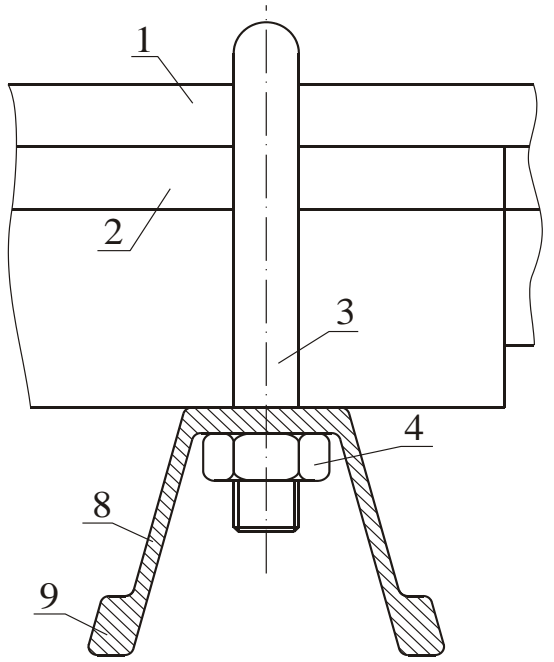

(b) - side view

Fig. 3. Support section in interlock zone 
The support has element 1 (beam) and element 2 (stand) connected by an interlock; the support has cramp 3 with nuts 4 and strip 4 in the form of a section of a special structural iron with holes 6 in the bottom 7 of a strip pan. Walls 8 and flanges 9 of a strip form strengthening ribs.

When a flexible unit is setting up, support elements 1 and 2 are connected with overlap by cramp 3 , nuts 4 and strip 5 . Holes 6 for the cramp 3 are made in the bottom 7, and nuts 4 are placed inside strip pan 5 .

The forcing of contraction of support elements 1 and 2 is restricted by the strength of the thread on cramp 3, but even with such great forcing the strip 5 is not practically curved due to the great resisting moment determined by the strengthening ribs from wall 8 and the flanges 9 of strip 5 .

Thus, the small curve of strip 5 doesn't lead to cramp curve 3 in the thread zone and doesn't lead to stress concentration in the thread.

The possibility of support elements 1 and 2 contraction in a flexibility unit with greater forcing than in known constructions allows to reach support flexibility forcing equal to $0,6-0,7$ support load capacity in the tough condition.

Since contact stress between bottom 7 of strip 5 and element bottom 2 made of special structural iron is one order less than contact stress between cod cramp 3 and flange element 1 (beam), so with support functions in flexibility condition there is strip 5 sliding towards support element 2 (stand); and the support element 1 tail never goes out of the pan of the support element 2 (stand), while the support element 2 tail (stand) is sliding towards support element 1, it never loses contact with it, because this is the moment of flexure in flexibility unit zone according to stress curve in the support caused by rock pressure.

It leads to support forcing in flexibility condition increase.
The nuts 4 placement inside the pan of strip 5 requires the usage of a special key wrench with an offset handle, but such single complicating usage of proposed interlock for support elements from special structural iron is replaced by a simple flange construction and its significant low price due to a great number of waste products after support elements production; the flange interlock of support elements is made of these waste products.

The existing typical and unified sections of permanent horizontal and inclined mine openings with different type of support are limited by maximum cross section area in the clear $18-20 \mathrm{~m}^{2}$. Due to this reason in production projects clear openings of different sizes and forms with cross section area in the clear $18-20 \mathrm{~m}^{2}$ are developed and built if necessary. The developed metal frame, according to [6] [7] should pass approval tests. Their parameters (size, flexibility, load capacity, resistance, stable functioning in flexibility conditions) must correspond to the standards' requirements [6].

According to the analysis and requirements [6] [7], in JSC KuzNIIshahtstroy types of metal support of an arched form were developed [9]. The bench tests in tough and flexibility conditions were done [8] [11] [13].

In the result of approval tests of metal four and five unit arched support performed according to the standards requirements [7], the following was determined: frame load capacity $\left(F_{1}\right)$, specific gravity $\left(M_{g}\right)$, beam curve $\left(h_{\mathrm{b}}\right)$ for all the types of the support; the results are shown in Fig. 4, 5, 6.

According to the metal frame support in tough condition experiments' results and according to diagrams built on these results, it was estimated that the decrease of load capacity from 14,1 to $21,3 \%$ with other things being equal happens with an increase of cross section area; the specific gravity is changing a little to $4 \%$ or to the lower side to $2,7 \%$, and beam curve increases with the increase of cross section area of a support from 11,1 to $18,5 \%$.

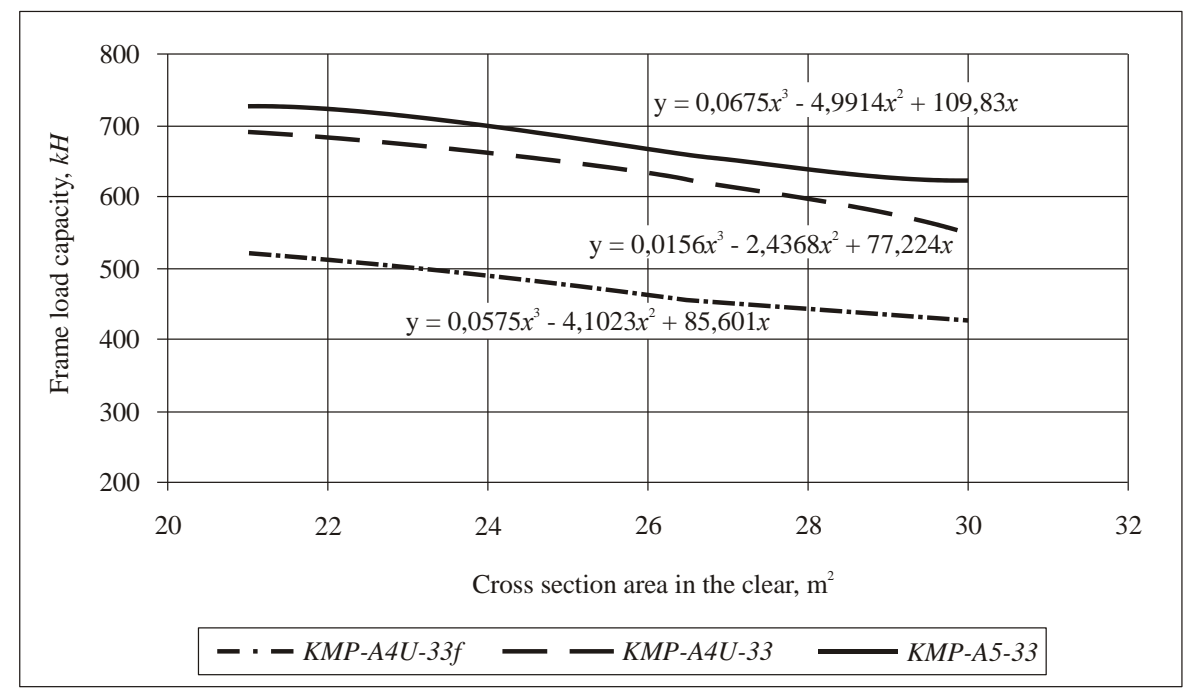

Fig. 4. The dependence diagram of load capacity of a support frame from its typical size 


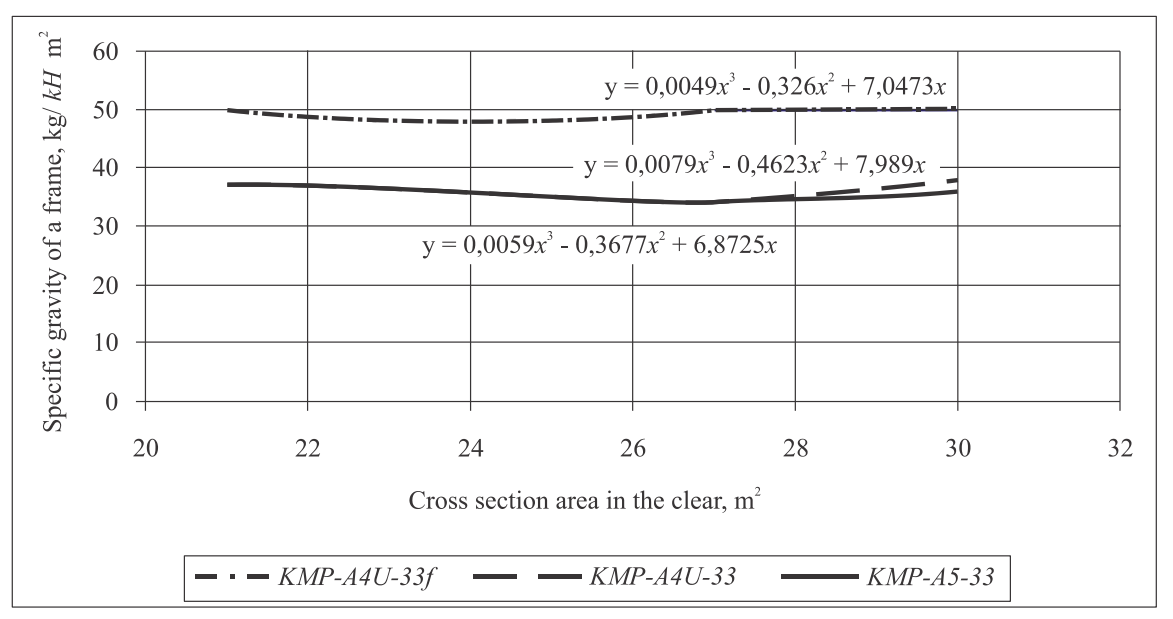

Fig. 5. The dependence diagram of specific gravity of a support frame from its typical size

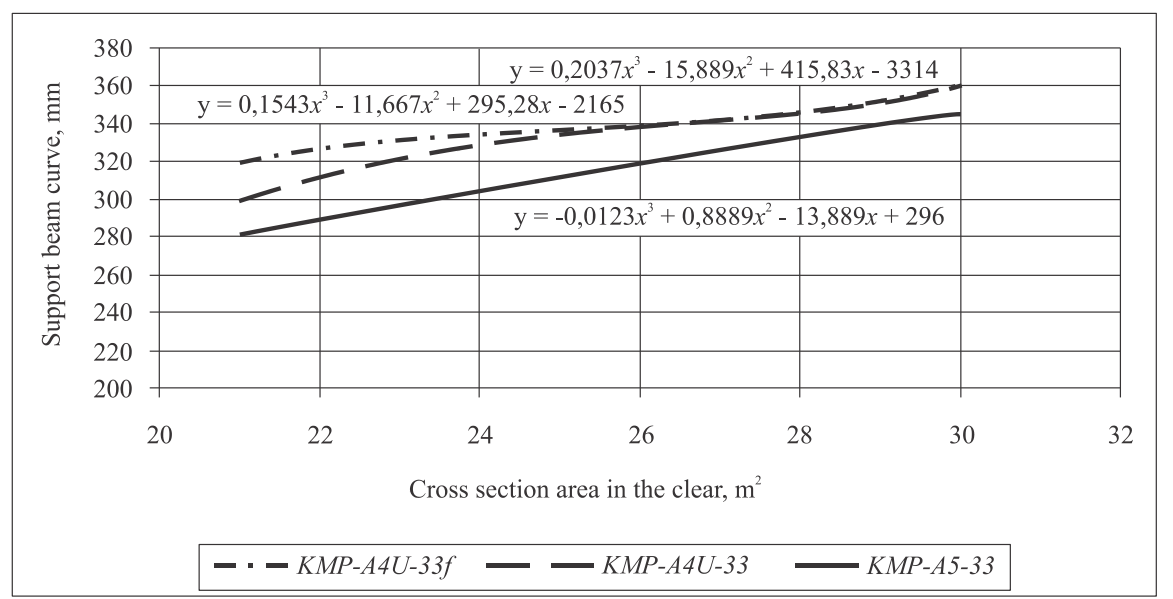

Fig. 6. The dependence diagram of a support frame of beam curve from its typical size

In the result of the support in flexibility condition tests the following was determined: vertical $(h)$ and horizontal $(v)$ constructive flexibility, overlapping at the end of tests is medium $\left(l_{\mathrm{fr}}\right)$, resistance $\left(P_{r}\right)$ (Fig. 7), time to failure $\left(T_{\mathrm{f}}\right)$ (Fig. 8), functioning stability $\left(K_{\mathrm{n}}\right)$, energy consumption $\left(P_{\mathrm{e}}\right)$ (Fig. 9) to all support typical size.

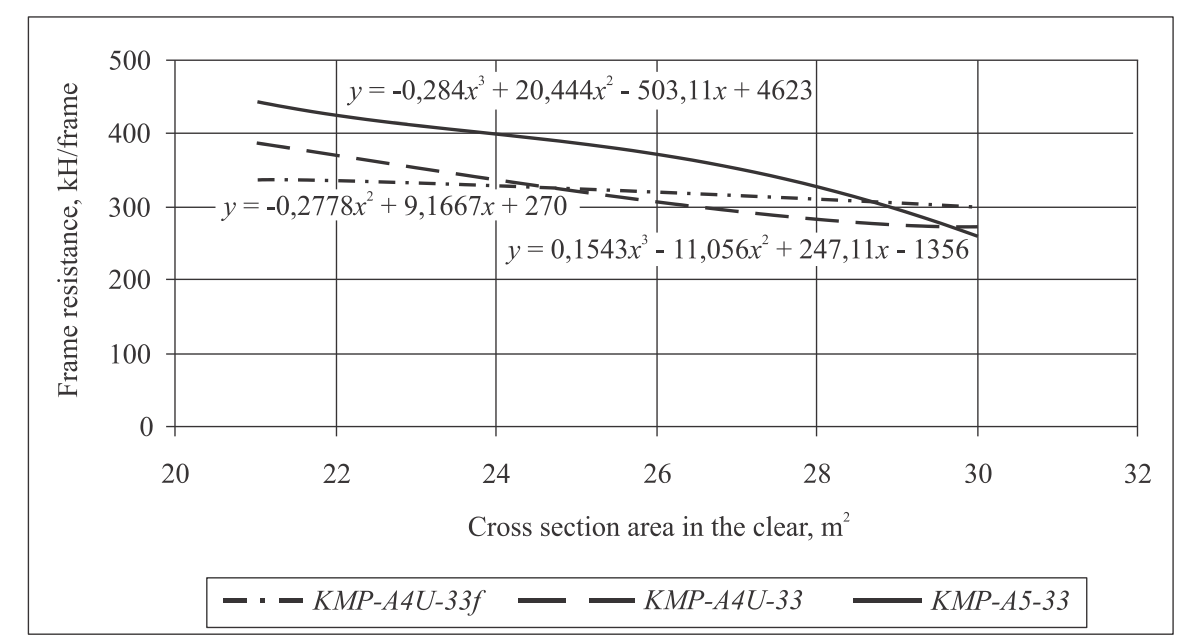

Fig. 7. The dependence diagram of resistance of a support frame from its typical size 


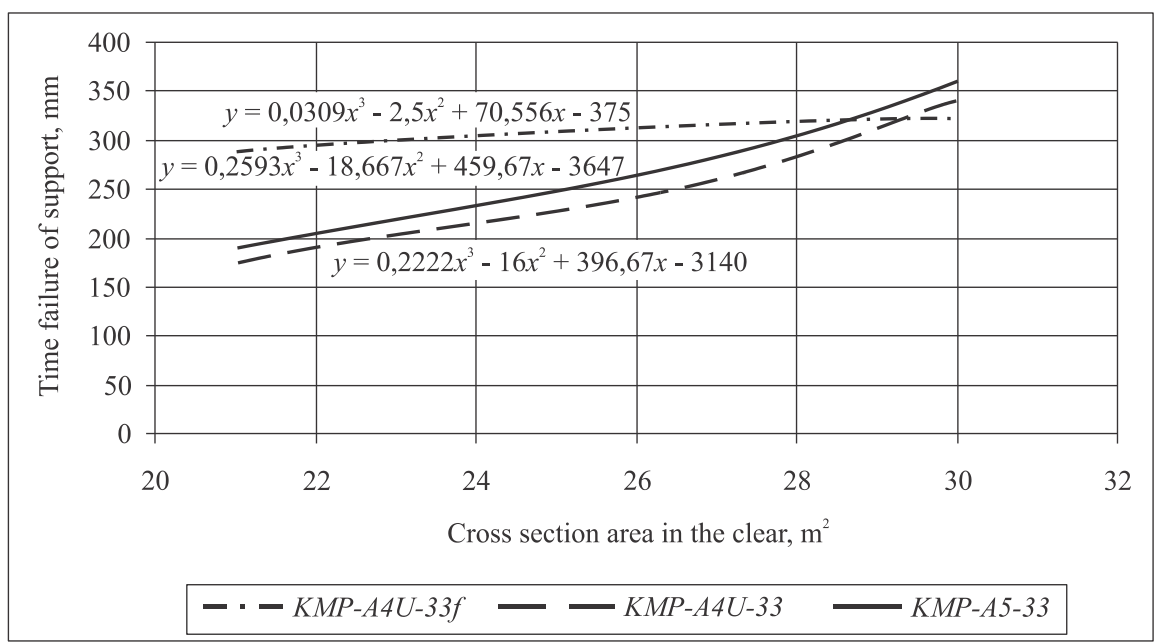

Fig. 8. The dependence diagram of time failure of a support from its typical size

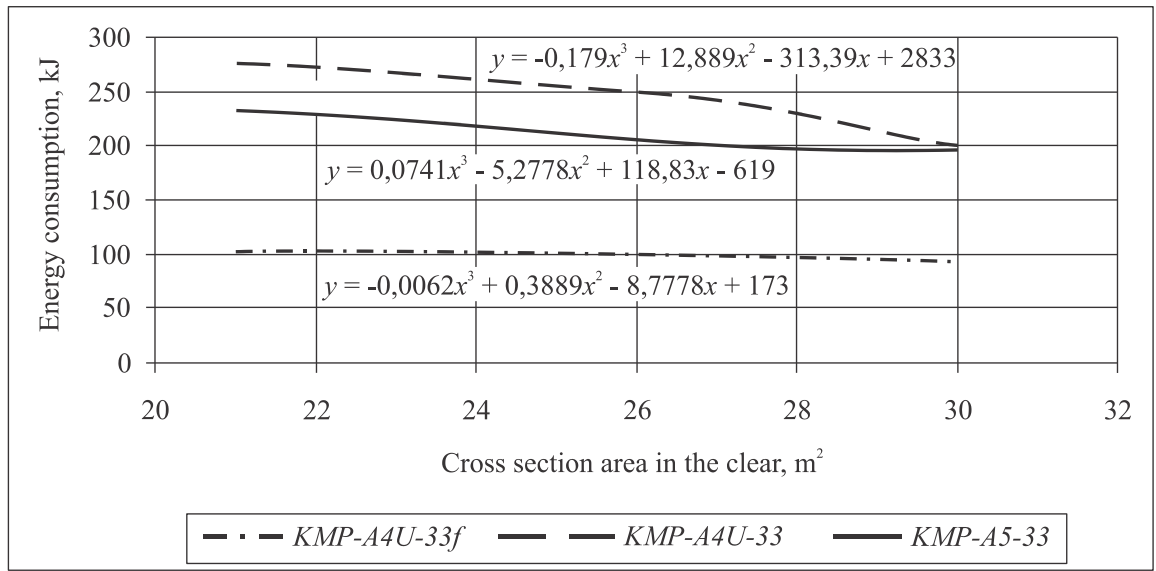

Fig. 9. The dependence diagram of support energy consumption from its typical size

According to the metal frame support in flexibility condition experiments' results and according to dependences, it was estimated that decrease of resistance from 13,2 to $40,8 \%$ with other things being equal happens with increase of cross section area; the time failure in some cases increases a little by $10 \%$, but in some cases by $49 \%$, energy consumption decreases with increase of cross section area of the support from 9,7 to $28,8 \%$.

\section{RESUlTS}

The results of performed experiments became the foundation to develop a reinforced concrete support of inclined shaft collars for mines under construction and reconstruction in Kuzbass (Fig. 10).

The peculiarity of support construction improvement is the fact that it consists of covered by mesh-wire-lagging of a metal arched support from special structural iron 1 with junctions 2 between stands 3 and beams 4 , placed respectively at the inside surface of the vertical part and the outside surface of the upper curve section of a concrete support 5. Additional mesh-wire-laggings 6 and 7 (not connected with each other) are installed respectively at the inside surface of the curved section and at the outside surface of the upper curve section of the concrete support 5 (Fig. 10) [12] [14] [15].

The support is installed in a roadway with some gap from the side walls; and frames of a metal arched support with junctions 2 between stands 3 and beams 4 are installed close by upper point, mesh-wire-lagging is fixed on the frames.

Later at some distance from the face near additional reinforcing wire-mesh 7 is installed and additional reinforcing net 6 is stringed to beams 4 .

The upper tails of nets 7 are higher than low tails of nets 6 (practically upper and lower of junctions 2). 


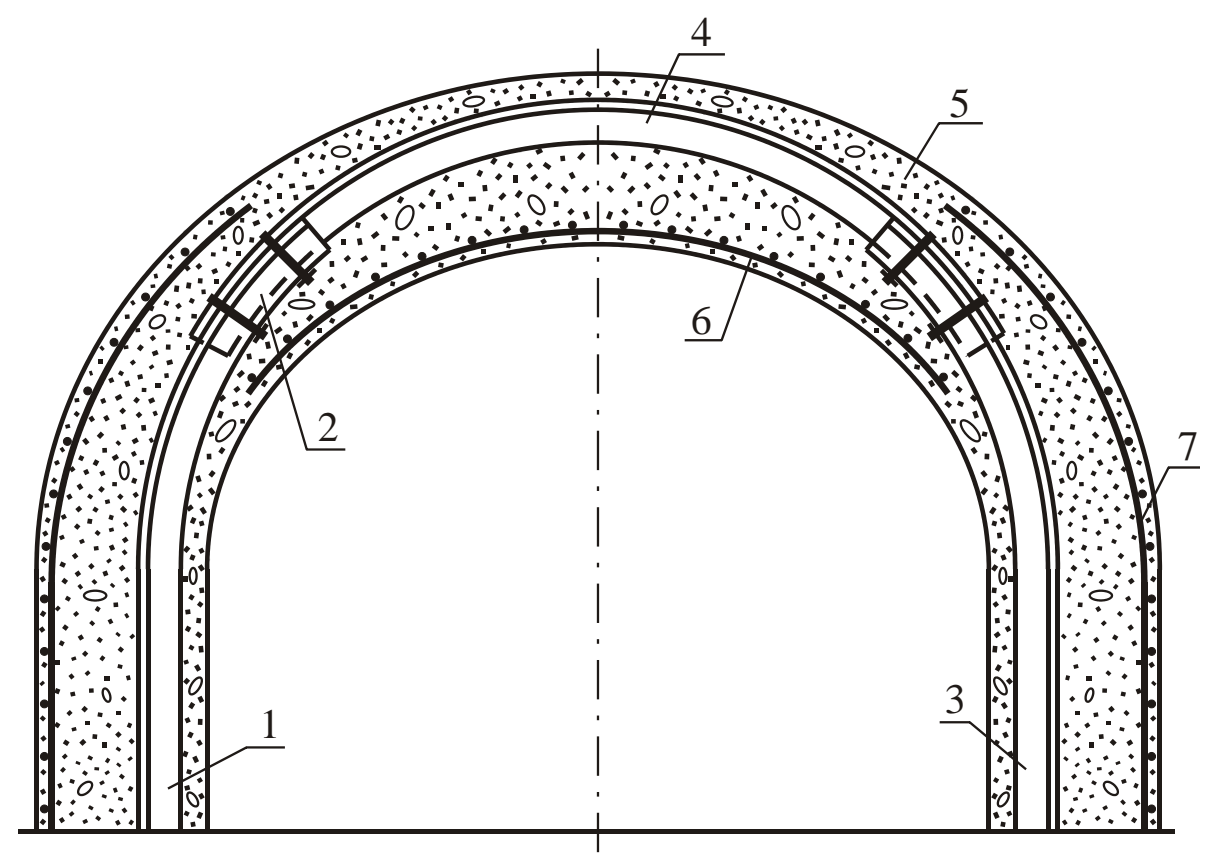

1 - metal frame from SVP; 2 - interface node; 3 - stands;

4 - beam; 5 - cast-in-place concrete; 6 - low mesh reinforcement; 7 - upper mesh reinforcement;

Fig. 10. Cast-in-place concrete support with flexible reinforcing in a support section

\section{CONCLUSIONS}

During the construction of the mouths of inclined shafts, application of a designed cast-in-situ concrete support structure can give:

1. The direct economic effect - material savings due to increased installation length of metal frame support; reduction of thickness of the cast-in-situ concrete support, and, as a consequence, reduction of excavation volume.

2. The indirect economical effect from new type of interlock application is the following: expenses decrease on materials delivery to roadways; increase of rate for mining operations due to increase of machine working rate during shifts.

\section{REFERENCES}

[1] Nasonov I. D., Resin V. I., Shuplik M. N., Fedukin V. A. Technology construction underground buildings. Construction horizontal and inclined mine openings / textbook for high school. - Moscow : Publishers Academies of the mountain sciences, 1998. - $317 \mathrm{p}$.

[2] Karetnikov V. N., Klejmenov V. B., Nuzhdihin A. G. Supports capital and starting-up mine openings / reference book. - Moscow : Depths, 1989. $571 \mathrm{p}$.

[3] Kosarev N. F., Kopytov A. I., Pershin V. V., Vojtov M. D. Construction inclined mine openings. - Kemerovo : Kuzbassvuzizdat, 2004. - 347 p.

[4] VG 91.13330.2012. Underground roadway support. Actualization of release BNaR II-94-80 - Moscow : Russian Ministry of region, 2012. $54 \mathrm{p}$.

[5] Mine and underground construction : to 2 t. T. 1 : textbook for high school / B. A. Kartoziy [and other]. - Moscow : Publishers MSMU, 2003. $-732 \mathrm{p}$.
[6] STANDARD R 51748-2001. Metal flexible frame supports. Arched support. General technical conditions : used since 01.01.2002. Moscow : Russian State standards, 2001. - 12 p.

[7] STANDARD R 50910-96. Metal flexible frame supports. Experimental methods : used since 01.01.1997. - Moscow : Russian State standards, 1996. $-11 \mathrm{p}$.

[8] Vojtov M. D., Budnikov P. M., Vashhenko S. G. Investigation of support load capacity KMP-A3M from special section SVP // XIII International scientific-practical conference "Natural and intellectual resources of Siberia". Kemerovo October 28-29, 2010. pp: 228-231.

[9] Vojtov M. D., Pershin V. V., Budnikov P. M., Makarenko A. I., Purtova T. E. Interlock to support elements of the special structural iron. Patent \# 77906. Reiterated in State list-register of useful models of the Russian Federation at 10.11.2008.

[10] Voitov M. D., Budnikov P. M. Metal arched supports from special structural iron. Patent \# 122440. Reiterated in State list-register of useful models of the Russian Federation at 27.11.2012.

[11] Vojtov M. D., Vashenko S. G., Budnikov P. M. Research and analysis of bench and approval tests of metal arched supports from SVP. - Vestnik Kuzbass. gosud. tehn. univ.2011. \# 6. pp: 21-25.

[12] Vojtov M. D., Pershin V. V., Budnikov P. M., Sadikov K. V. Roadway support. Patent \# 59726. Reiterated in State list-register of useful models of the Russian Federation at 27.12.2006.

[13] Budnikov P. M. The results of tests of interlock arched support in tough and flexibility conditions from SVP-33 for slope mouth. - Vestnik Kuzbass. gosud. tehn. univ. 2014. \# 6 pp: 43-46.

[14] Pershin V. V., Vojtov M. D., Cherdantsev S. V., Budnikov P. M., Lebedev A. A. Upgraded technical decisions for lining and maintenance of mine workings. Advances in geotechnical and structural engineering : Proceedings of the Fifth China-Russia Symposium on Underground and Building of City and Mine - 26-28 Sept. 2008, Qingdao, China. pp: 50-52.

[15] Budnikov P. M. New methods support of slope mouth. Materials of IX international research and practice conference "East partnership - 2013". section 32. Building and architecture. Science and studies. 07-15 sen. 2013. s. 28-33 [07-15 sep. 2013. pp: 28-33]. 